\title{
Tender Shoots: Effects of a Preschool Shared Book Reading Preventive Intervention on Parent-Child Reading and Parents' Involvement in the First Year of School
}

\author{
Sarah Timperley ${ }^{1} \cdot$ Elizabeth Schaughency $^{1}$ (i) $\cdot$ Jessica Riordan ${ }^{1} \cdot$ Jane Carroll $^{1} \cdot$ Shika Das $^{1} \cdot$ Elaine Reese $^{1}$
}

Accepted: 31 January 2022 / Published online: 26 February 2022

(c) The Author(s) 2022

\begin{abstract}
Parent-child interactive shared reading can benefit young children's language and emergent literacy skills; however, studies of programs to enhance shared reading often do not evaluate lasting effects after the transition to primary school. In this randomized control study, 69 parents of 3.5-4.5-year-old children participated in one of three conditions for an evaluation of the 6-week Tender Shoots program: Rich Reading and Reminiscing (RRR), Strengthening Sound Sensitivity (SSS), or Activity-Based Control (ABC). Parents in both Tender Shoots conditions, SSS and RRR, were taught to read interactively with their children and were provided with books to support implementation. RRR targeted meaning-related talk likely to enhance vocabulary and comprehension, whereas SSS targeted sound-related talk to enhance phonological awareness. Children in $\mathrm{ABC}$ were provided with resources and materials for developmentally appropriate activities. Fifty-three dyads (77\%) were followed after children started primary school and formal literacy instruction. Comparisons of shared reading interactions at follow-up indicated that parents and children in the RRR and SSS groups still used more condition-specific targeted talk than those in other groups. Most parents in shared reading groups reported that they continued to use project activities after children had started school, although parents in RRR reported more frequent use of program activities than the active control, ABC. Moreover, parents in RRR sometimes reported higher levels of some broad involvement dimensions. These findings suggest that shared reading programs as delivered here can have long-lasting effects on extratextual talk during shared reading and may enhance aspects of parents' involvement with children's education.
\end{abstract}

Keywords Shared reading $\cdot$ Parent involvement $\cdot$ Home literacy $\cdot$ Preventive interventions $\cdot$ Kindergarten

At the time this research was conducted, Sarah Timperley, Jessica Riordan, and Shika Das were graduate students in the Department of Psychology at the University of Otago. The data presented here were included in the Ph.D. research of Dr. Timperley.

Elizabeth Schaughency

schaughe@psy.otago.ac.nz

Sarah Timperley

sarah.jane.timperley@gmail.com

Jessica Riordan

jessica.riordan@postgrad.otago.ac.nz

Jane Carroll

jane.carroll@otago.ac.nz

Shika Das

shika_108@hotmail.com

Elaine Reese

ereese@psy.otago.ac.nz

1 Department of Psychology, University of Otago, Dunedin, New Zealand

\section{Introduction}

Research indicates that children from diverse backgrounds come to school with differing language and emergent literacy skills predictive of later school achievement (Greenwood et al., 2017). This knowledge has led to initiatives designed to foster children's language competencies before school, often resulting in positive initial gains (Greenwood et al., 2017; Petscher et al., 2020). These evaluations, however, often do not follow children's progress after the transition to school, and those that do show mixed effectiveness depending on the initial program and how parents and teachers continue to build on children's learning (Dowdall et al., 2020; Sarama \& Clements, 2018). In some studies, fadeout occurs, where positive effects shown immediately after program participation disappear over time (Barnett, 2011). Fade-out may be particularly likely across transitional periods, such as when children start formal education (Sarama 
\& Clements, 2018). It is therefore important to investigate whether and under what circumstances parent-mediated preventive interventions for preschool children continue to demonstrate benefits after the transition to formal schooling, and whether they impact parents' involvement in children's learning and their relationships with schools more broadly.

Parents' involvement in children's education is generally positively associated with children's learning and adjustment (Kim \& Sheridan, 2015). Family involvement in elementary school can support children's academic achievement and offset educational risk often associated with low socioeconomic status (SES; Boonk et al., 2018), leading to calls for urgent efforts to engage families in their children's education (McWayne, 2015). Randomized control trials are needed to examine program effects on engaging family involvement (see Garbacz et al., 2017).

\section{Parents' Involvement with Children's Learning}

Despite consensus on the importance of connections between families and schools for children's developmental success, there is no single agreed-upon definition of parental involvement (Boonk et al., 2018; Kim \& Sheridan, 2015). In this paper, we draw on conceptualizations of parental involvement that focus on parental activities or behaviors to benefit children's learning and development (Kim \& Sheridan, 2015), with three broad types of involvement described in the parent involvement literature: home-based involvement, school-based involvement, and home-school communication (e.g., Fantuzzo et al., 2000; McDowall et al., 2017).

Positive associations with children's academic outcomes have been reported for different forms of involvement (Kim $\&$ Sheridan, 2015), although findings may vary across type of involvement, academic domain, and/or developmental window (Boonk et al., 2018). Therefore, for conceptual clarity, Boonk et al. (2018) recommended researchers specify the nature of involvement under study to identify developmentally beneficial forms of involvement. In their review, Boonk et al. (2018) identified two forms of homebased involvement, i.e., reading at home and engagement in learning activities at home, as promising forms of involvement during early childhood, with positive associations for children's academic outcomes. Moreover, parents' involvement with reading at home was again identified by Boonk et al. (2018) as a promising form of involvement during early elementary school and reading acquisition, positively associated with later achievement, particularly in oral language and literacy.

Direct positive associations between academic achievement and other forms of involvement are sometimes, but not always, found in parent involvement research focusing on the early years (Boonk et al., 2018). In addition to achievement, parents' engagement in education is associated with children's adjustment in a number of areas (Kim \& Sheridan, 2015). School-based involvement and home-school communication may provide opportunities for families to interact with school personnel, important to forming connections and building relationships with school personnel, in turn fostering engagement (see McDowall et al., 2017). However, research suggests school-based involvement (Fantuzzo et al., 2000) and home-school communication (Rimm-Kaufman \& Pianta, 1999) may be higher in preschool than in elementary school.

The transition to formal schooling can be challenging for parents. As children start formal education, many parents want to continue to support their child's learning but may not understand the goals, expectations, and teaching techniques used in classrooms, making this support difficult. Parents are more likely to be involved in children's homeand school-based learning when they feel their involvement is encouraged and valued by their children, teachers, or school personnel, and when they feel that their help is effective (Green et al., 2007; McDowall et al., 2017). Indeed, when parents' sense of efficacy for supporting their children's learning increases, there is a corresponding increase in home-based learning activities, such as listening to their child read (McDowall et al., 2017). Parents are also more likely to contribute to their children's learning when teachers believe parent help is useful (McDowall et al., 2017).

Providing parents with specific ways to support their children's learning may have broader benefits for parent involvement (Sabol et al., 2018). This collateral benefit has been illustrated in early childhood (DeLoatche et al., 2015). DeLoatche and colleagues found that parents who participated in a parent-mediated domain-specific early literacy program for preschoolers increased domain-general involvement in children's learning at home compared to controls, although they did not find benefits for school-based involvement or home-school communication. These results are promising; however, there was no follow-up to assess whether effects persisted after children started school.

Consistency of learning across settings has been discussed in terms of children's learning (e.g., Sarama \& Clements, 2018), but it may also be important for parents to see a continuity between their own interactions with their child and what their child is learning at school. This consistency between home and school learning may be especially important for fostering parent-teacher relationships (Garbacz et al., 2017). Therefore, when designing parent-facilitated language and early literacy programs, it may be important to consider how these strategies might continue to support children's learning once school starts. Parents' continued use of these skills after formal schooling begins may continue to augment children's skills and strengthen parents' involvement in their children's learning. 


\section{Shared Book Reading as a Form of Parental Involvement in Children's Learning}

In New Zealand (NZ), the setting for this study, parents report reading with their preschoolers regularly (Morton et al., 2017; Riordan et al., 2018), and they have identified shared reading as a preferred focus for parent-mediated early language and literacy programs (Schaughency et al., 2016). Shared book reading is an excellent potential medium for teaching preschool children language and emergent literacy skills, especially when parents use extratextual talk scaffolded to the child's level of development (Flack et al., 2018; Petscher et al., 2020). Extratextual talk refers to talk during reading that is not part of the text, including book-related talk immediately before and after reading. Once children start formal schooling and begin reading instruction, the perceived function of shared reading often changes, as some parents begin to help their children to read (Sénéchal et al., 2017). This change can benefit children's reading acquisition; however, children may also benefit from parents' continued use of crucial language and comprehension-building extratextual talk (Reese, 2013). Therefore, it is important to examine how parents continue their involvement in their children's reading after school starts. This study investigates whether parent-child dyads who participated in a preschool shared reading program show condition-specific shared reading practices and broader parent-reported involvement after school entry.

Shared reading programs typically take one of two approaches (Riordan et al., 2021). Meaning-based approaches focus on strategies that encourage children to think about the characters, story, meanings of words, and relationships with real life. Code- and sound-based approaches focus on drawing children's attention to aspects of print and/or the sounds within words. Children's awareness of individual speech sounds, phonological awareness, is predictive of later literacy skills (Petscher et al., 2020).

Flack et al. (2018) showed through meta-analysis that preschool children learn more words from picture books when the reader engages children with meaning-related extratextual talk. Likewise, Riordan et al. (2018) showed a relationship between the proportion of parents' naturally occurring extratextual prediction and inference comments and their 3-5-year-old children's prediction and inference scores on a story-based listening comprehension task. In contrast, parents' extratextual talk about sound and print concepts showed positive relationships with children's phonological awareness.

Programs focused on promoting extratextual talk during shared reading increase parents' use of specific types of targeted talk which in turn increase preschool children's emergent language and literacy skills (Dowdall et al., 2020; Riordan et al., 2021). These programs have shown positive results for preschool children's early language skills (e.g., vocabulary and comprehension) and emergent literacy skills (e.g., print knowledge and phonological awareness) (Dowdall et al., 2020; Riordan et al., 2021). Variants of these shared reading programs have also been effective when used in classrooms with 5-year-olds (e.g., Gillon et al., 2019), showing that school-age children can continue to benefit from these interactive shared reading approaches. Interactive shared reading in dyads or small groups provides children opportunities to respond and ask questions and allows adults to scaffold children's learning. Thus, parent-child shared reading at this age has the opportunity to be continue to be useful for children's learning (Sénéchal et al., 2017). Maintaining these important high-quality reading interactions with parents may be beneficial for the parent-child relationship (Canfield et al., 2020) as well as children's engagement with reading more broadly (Reese, 2019).

In the first years of primary school and formal reading instruction, the nature of shared reading can change significantly, as many parents pass on the reading of the book to their children (Sénéchal et al., 2017). There may be several reasons why parents are less inclined to continue to use interactive techniques once the context shifts to listening to their children read. For one, the books read by beginning readers often differ from storybooks read to children: These books tend to contain simpler language, concepts, and plotlines than those read for leisure (Ministry of Education, 2014; Reese, 2013). The perceived function of shared reading also changes, as parents begin to help their children learn to read (Sénéchal et al., 2017). While child-to-parent reading is important to support reading acquisition (Sénéchal \& Lefevre, 2014), there is a risk that parents may stop reading more challenging books to their children and using rich extratextual dialogue to support children's engagement and understanding (Reese, 2013). However, quality parent-tochild shared reading with cognitively challenging content and unfamiliar vocabulary is still important for school-age children's developing oral language and comprehension skills (Suggate et al., 2013).

Many studies of early reading programs do not measure parents' use of the techniques taught, whether and how they continue to use them after the intervention has ended, or whether features of the interventions encourage longerterm benefits. In particular, there is a notable lack of randomized controlled evaluations of shared reading programs that follow participating parents and children after school starts (Dowdall et al., 2020). As evidence suggests that the effectiveness of shared reading programs is mediated by whether and how parents use the strategies taught, it is important to evaluate whether the skills taught to parents during preschool are still used after this transition (Murray et al., 2016). Considering the potential impact of encouraging interactive shared reading on family involvement (e.g., 
DeLoatche et al., 2015), and the call for randomized control trials to show ways in which family involvement can be encouraged (e.g., Garbacz et al., 2017), effects of parent programs on involvement after the transition to school and beginning literacy instruction should be evaluated.

\section{The Current Study}

This study follows children and parents 1 year after they participated in a parent-mediated preschool shared reading program called Tender Shoots. We investigate whether the skills learned in two shared reading conditions are still being used by parents and children, relative to a non-shared reading control condition, now that children are in their first year of school and have begun formal literacy instruction. One condition, Rich Reading and Reminiscing (RRR), focused on increasing extratextual talk to promote comprehension and language development. The other, Strengthening Sound Sensitivity (SSS), focused on sound talk to promote phonological awareness. Previous evaluations found both to be feasible (Schaughency et al., 2014) and to be associated with condition-specific changes in parent-child interactions and on children's skills at posttest (Riordan et al., 2021). Evaluations at posttest suggested that overall, families implemented the majority of project activities $(M=83 \%)$, although documented implementation varied across families $(0-100 \%$ of project activities). Our main aims were to investigate parents' continued use of project activities and whether condition-specific changes in parent and child extratextual talk were still present 1 year post-participation, after children had transitioned to school. Our secondary aim was to investigate whether there were additional benefits of the shared reading programs for parents' involvement in children's learning more generally across the home, school, and home-school communication domains.

\section{Method}

This paper is part of a larger study (Schaughency et al., 2014). Baseline (Riordan et al., 2018) and immediate posttest (Riordan et al., 2021) data are presented elsewhere, as are 1-year follow-up data for children's oral language (Reese et al., under review) and progress in beginning reading (Schaughency et al., 2021).

\section{Participants}

Recruitment, allocation, and retention are shown in Fig. 1. Three- to 4.5-year-old children and their parents were recruited as volunteers through eight early childhood centers in a small NZ city.
Fifty-three families participated in 1-year follow-up; however, ns varied by analysis, due to incomplete data (see Fig. 1). Specifically, fifty parents were audio-recorded reading books with their participating child at pretest and 1-year follow-up. One dyad was excluded from analyses of shared book reading because the parent did not read the text. Fiftyone parents returned questionnaires at pretest and 1-year follow-up. Of these, two were excluded from analysis of the family involvement questionnaire (FIQ), one because their child had not yet started school at 1 year follow-up and the other because the participating parent worked at their child's early childhood center, influencing pretest schoolbased involvement and home-school communication scores. Two participants were also excluded in these analyses due to missing questionnaire data at baseline, leaving 47 participants with completed parent questionnaires at both pretest and 1-year follow-up. Three participants were excluded from analyses of implementation data (project activity stamp charts) because they only returned the first week's stamp chart.

\section{Demographic Characteristics}

Demographic data were collected at pretest via questionnaire, except school decile, which was determined at 1-year follow-up. Demographic characteristics of the full-sample of participating parents are presented in Riordan et al. (2021). At follow-up, ethnicity data were available for 51 children. Children's parents identified 49 children as NZ European, with seven also identified as Māori, one also Chinese, one also British and one also Dutch. One child was identified as Middle Eastern, and one as Japanese and German. At follow-up, all participating parents were mothers. Mothers' highest educational qualification was measured on a scale where $0=$ no education, $1=$ primary school, $2=$ intermediate, $3=$ completed some high school, $4=$ completed high school, $5=$ polytechnic qualification, $6=$ university degree, and $7=$ postgraduate qualification. Mothers' age was collected by an item with response options in 5-year intervals, from $0=20$ or under to $9=$ over 60 . Employment was coded using the quartile scale on the New Zealand Socioeconomic Index (NZSEI-13), which uses occupation to estimate SES from 1 (highest quartile) to 4 (lowest quartile) (Fahy et al., 2013). For household highest employment, the highest of the mother's or father's NZSEI-13 was taken, consistent with the approach taking in other research examining the association between SES and literacy achievement (e.g., NonoyamaTarumi \& Willms, 2010).

Parents in NZ may choose which school their children attend (Ministry of Education, 2019), and at follow-up children attended 22 different schools. In NZ, schools are assigned a decile rating by the Ministry of Education to describe SES composition of the school community, such 
Fig. 1 Flowchart describing participation and retention of participants by group: Rich Reading and Reminiscing (RRR), Strengthening Sound Sensitivity (SSS), or ActivityBased Control (ABC). Randomization occurred within early childhood center

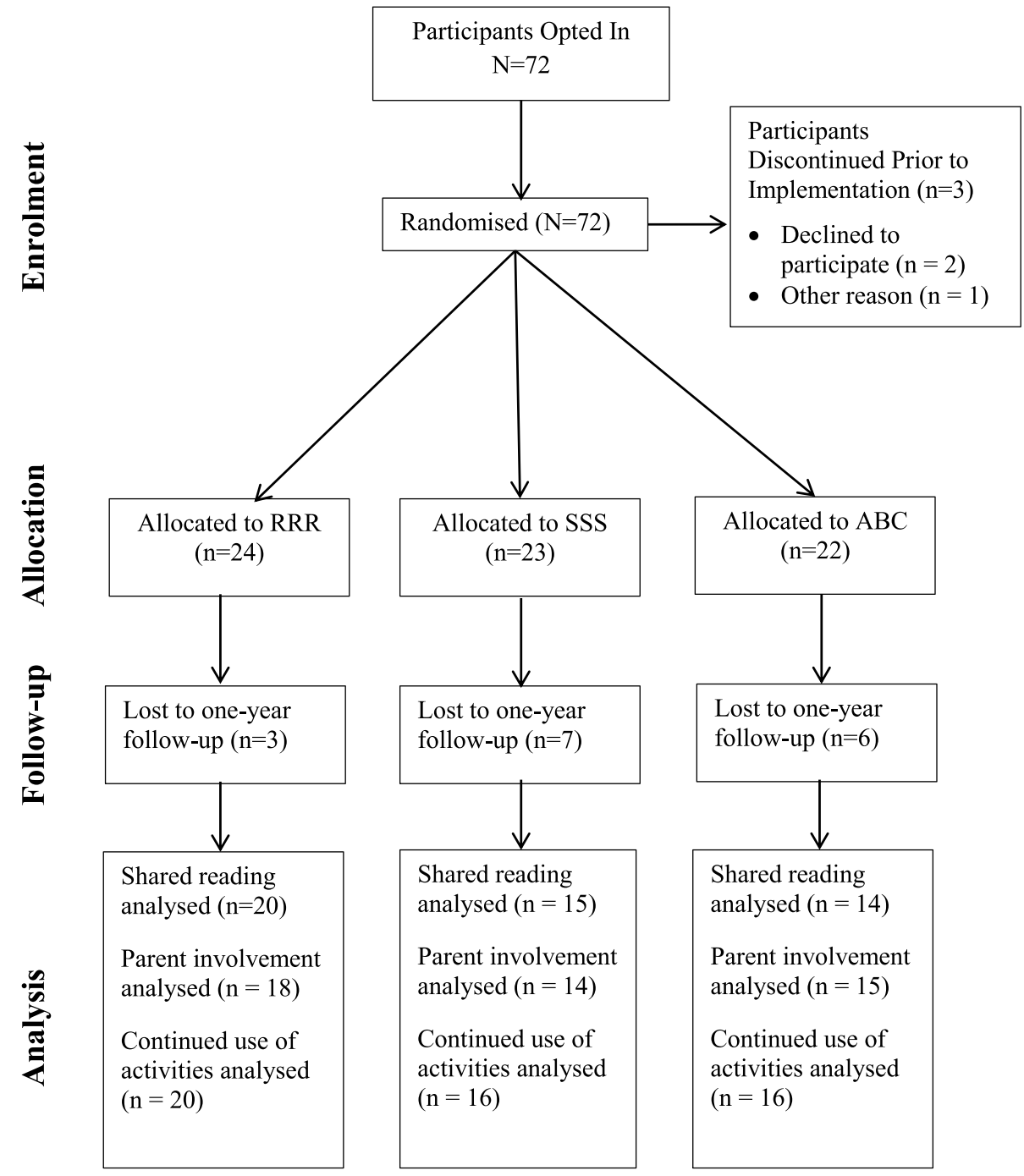

that schools assigned a rating of 1 are comprised of the highest proportion of students from low-SES communities and those assigned a 10 the lowest proportion (Ministry of Education, 2018). Demographic data are shown by group in Table 1.

\section{Attrition and Group Composition}

Attrition analyses compared parents who completed reading sessions and/or 1-year follow-up questionnaires $(n=53)$ to those who did not $(n=14)$ via independentsamples $t$ tests on pretest and demographic characteristics. Bias-corrected accelerated (BCa) bootstrapping was used to estimate confidence intervals (see Table 1). Chi-square tests were used to test for differential attrition as a function of child gender, mother work status, and group assignment. The only difference found was that families lost to followup had lower levels of implementation of project activities during participation (see "Measures" for description of "Implementation Check" section), $M(\mathrm{SD})=.607(.311)$ than those with follow-up data, $M(\mathrm{SD})=.818(.157), \mathrm{BCa}$ CI $[-.406,-.026]$. All other BCa bootstrap confidence intervals included zero and chi-square tests indicated no statistical differences between those with and without follow-up data.

Univariate ANOVAs with bootstrapping were performed to investigate possible differences in demographic and measured pretest variables between preventive intervention conditions for participants included in follow-up. No statistical demographic differences between groups were found. However, groups differed on some pretest extratextual talk measures. Significant ANOVAs were followed up by independent $t$ tests on means between groups. In some cases, the SSS group obtained higher average scores on extratextual talk variables at pretest than at least one other group. Preexisting differences potentially attenuated the power to detect differences in analyses of 
Table 1 Demographic variables by preventive intervention condition

\begin{tabular}{lllll}
\hline Variable & RRR & SSS & ABC & Overall \\
& $M(\mathrm{SD})$ & $M(\mathrm{SD})$ & $M(\mathrm{SD})$ & $M(\mathrm{SD})$ \\
\hline$N$ & 21 & 16 & 16 & 53 \\
Child & & & & \\
$\quad$ Age in months (pre) & $51.0(4.84)$ & $50.8(4.64)$ & $50.3(3.72)$ & $50.8(4.39)$ \\
$\quad$ Percent female & $47.6 \%$ & $37.5 \%$ & $37.5 \%$ & $41.5 \%$ \\
$\quad$ School decile (follow-up) & $7.00(2.00)$ & $6.13(2.16)$ & $7.13(2.27)$ & $6.83(2.15)$ \\
Mother & & & & \\
$\quad$ Highest education & $5.10(1.29)$ & $5.13(1.63)$ & $4.87(1.64)$ & $5.04(1.48)$ \\
$\quad$ Age & $3.70(1.22)$ & $3.56(.964)$ & $4.00(1.25)$ & $3.75(1.15)$ \\
$\quad$ Percent employed & $80 \%$ & $78.6 \%$ & $61.5 \%$ & $74.5 \%$ \\
$\quad$ Employment type & $2.19(.981)$ & $1.81(1.25)$ & $1.75(.707)$ & $1.97(1.01)$ \\
Household & & & & $1.78(1.01)$ \\
$\quad$ Highest employment & $1.95(1.08)$ & $1.64(1.01)$ & $1.69(.947)$ & \\
\hline
\end{tabular}

Preventive intervention conditions are Rich Reading and Reminiscing (RRR), Strengthening Sound Sensitivity (SSS), and Activity-Based Control (ABC). School decile is measured from 1 (lowest) to 10 (highest). Mother education is rated from 0 (no formal education) to 7 (postgraduate qualification). Mother age was measured between 1 (20 or under) and 9 (over 60). Employment type was measured from 1 (highest quartile) to 4 (lowest quartile) estimated marginal means of the SSS group at posttest. Instances of heteroscedasticity are noted in the results.

\section{Measures}

\section{Implementation Check}

To provide a measure of adherence during the implementation phase, weekly stamp charts were used to measure implementation of project activities. These had sections to "stamp" for each project activity to be completed. The total number of stamped activities per participant were counted and divided by the possible number of activities.

\section{Shared Reading Interaction}

At pretest and 1-year follow-up, parents were audiotaped reading unfamiliar children's books with their child "as they usually would" to assess competence in skill use. Because of developmental changes in children's comprehension of narratives, these observations included two shorter books at pretest and one longer book at 1-year follow-up. Recordings of parent-child reading sessions were transcribed fully and then coded reliably using two schemes (for pretest, see Riordan et al., 2018). The first scheme requires every extratextual proposition to be coded into mutually exclusive types of questions (open or closedended), statements, or other (e.g., confirmation, clarification etc.). Questions and statements are then coded according to meaning category (description, prediction/inference, relating to world, relating to own experiences, evaluations, and talk about print concepts; see supplementary material). The second scheme coded talk about sounds, such as rhyme, onomatopoeia, first sounds, and compound words. For both schemes, parent and child utterances were coded and entered separately. Transcribing and coding of 1-year follow-up data were conducted by advanced undergraduate and graduate psychology students who were blind to condition. The first author transcribed 1-year follow-up interactions. An advanced psychology undergraduate student went over all transcripts, listening to recordings and checking for errors. A randomly selected $25 \%$ of the follow-up transcripts were coded to assess inter-rater reliability. There was substantial agreement for meaning-related talk coded by these two researchers (Cohen's kappa of .77 for parents, .78 for children; see Landis \& Koch, 1977). The remainder of the meaning talk coding was completed by the undergraduate student, with oversight by the first author. The first and third authors completed reliability coding for sound-focused talk, achieving a kappa of .97 for parents and .95 for children, indicating near-perfect agreement (Landis \& Koch, 1977). The first author coded remaining transcripts for sound talk.

Two shorter books were read at baseline, containing a total of 111 total propositions across pretest books. There were 89 propositions in the one longer book read at 1-year follow-up. Therefore, the number of utterances in each category was divided by number of propositions in each book to calculate the number of parent or child propositions per book proposition. We created two "total talk" variables: (a) summing all parent codes and all child codes, and (b) "total on topic talk" excluding off-topic talk, such as children and parents talking about the voice recorder. Two total meaning-related talk variables, one for parents and one for 
children, were created by summing all meaning variables except descriptions, considered as lower-level talk for this age-group (Riordan et al., 2018).

\section{Continued Use of Project Activities}

At 1-year follow-up, parents also answered the question "Are you still doing some of the activities you learnt during this program?", (yes, no), with the follow-up question "If so, how often are you doing the activities?". Answers to the followup question were given on a Likert scale from 1 (once every couple of weeks) to 6 (more than once a day). For analysis, these answers were scored from 0 (if they answered no to the first question) to 6 .

\section{Family Involvement Questionnaire-New Zealand (FIQ-NZ)}

Questionnaires included scales to assess multiple dimensions of parent involvement (Fantuzzo et al., 2000; Manz et al., 2004). Garbacz and Sheridan (2011) adapted the FIQ-Elementary (Manz et al., 2004) for NZ primary school settings. The FIQ-E is internally consistent in US samples (Manz et al., 2004). At pretest, items were selected from the FIQ-Early Childhood (FIQ-EC; Fantuzzo et al., 2000), informed by factor analyses of the FIQ-NZ (Garbacz \& Sheridan, 2011) completed by parents of school-age children (Garbacz et al., 2015) and specifically parents of children in their first year of school in NZ (McDowall et al., 2017). Selected FIQ-EC items were reviewed by members of the early childhood community and adapted for NZ early childhood settings. Pretest items assessed school-based involvement and home-school communication. The pretest questionnaire did not include home-based support for learning to reduce overall response burden, given other measures related to home literacy support at baseline (e.g., Riordan et al., 2018). At follow-up, participants completed items assessing all three scales based on the factor analyses of McDowall and colleagues (McDowall, 2014; McDowall et al., 2017). McDowall (2014; McDowall et al., 2017) showed these scales to have alphas of .69 (home-based), .81 (schoolbased), and .88 (home-school communication). In this study, we obtained alphas of .72 (home-based), .86 (school-based), and .90 (home-school communication) at follow-up. See supplementary materials for full questionnaire items and our reliability analysis results. Items were rated on a 4-point Likert-like scale, with 1 indicating a form of involvement rarely happens and 4 indicating always. Results are reported as the mean rating across items of each subscale.

\section{Study Overview}

Participants were randomly allocated within early childhood centers to one of the three conditions for a 6-week preventive intervention (see Fig. 1), and all were provided with weekly resources to support implementation (Riordan et al., 2021). Parents in the two shared reading conditions were lent the same 12 commercially available children's books. These were chosen by researchers to be enjoyable, developmentally appropriate, have a classic narrative plot, both pictures and text to discuss and, in about half, features such as rhyme and alliteration to draw attention to sound. Each book contained a series of condition-specific prompts for extratextual talk (see below; Riordan et al., 2021). Those in the control condition were given instructions and items to help complete developmentally appropriate non-reading activities such as color pencils, safety scissors, glue sticks, colored card, and other craft materials. To document implementation, all participants received weekly charts which parents were asked to have their children stamp after completing each activity. These were similar to those used during baseline assessments (Riordan et al., 2018) and were familiar and enjoyable for children (Schaughency et al., 2014).

\section{Book Reading Conditions}

In RRR and SSS, parents attended a 1-h education session to introduce the rationale for the shared reading approach and strategies to provide and encourage condition specific extratextual talk. In RRR, extratextual talk included the meaning of words and events, and the storyline and characters in the book. In SSS, it attended to sound features of words while reading (e.g., rhymes and onset phonemes). Participants then received 12 books over 6 weeks, with two books delivered weekly to their early childhood center.

Each book contained a series of prompts to model comments targeted in that condition, encouraging condition-specific interactions around the book. Dyads were asked to read each book three times, with prompts progressing from lower to higher cognitive demand. In RRR, first-reading prompts focused on vocabulary, understanding, and engagement (e.g., "this grassy part is called a meadow"), to later-reading prompts encouraging children's active involvement and more abstract thought about the characters and concepts in the book (e.g., "What is he thinking?), or recalling concepts previously discussed (e.g., Do you remember what "creaking" sounds like?). Dyads in RRR were also encouraged to reminisce about a personal experience related to the book after each reading (e.g., talk about a time they cooked or baked together after reading The Gingerbread Man). The reminiscing prompt for the first reading was for a shared positive experience; for the second, a time the child experienced a negative emotion; and for the third reading, a time the child experienced a positive emotion (see Salmon \& Reese, 2016 for rationale for conversations about shared emotional experiences). Prompts in SSS progressed from drawing attention to sounds focused on large phonological units such as rhyme 
(e.g., Bed, head; toys, noise; enough, fluff. Emphasize these rhyming words as you read them) to smaller units focused on individual phonemes (e.g., Bed, Bob, beans, bursting; creepy crawlies, curtains, crumpled, covered, ketchup. Emphasize and say, "This book has words that start with the same sound. B..ed, b..ob, b.eans and b..ursting all start with the / $b /$ sound"). In SSS, prompts for additional oral language interactions built on phonological concepts introduced during each reading (e.g., looking through books and pointing out things starting with the same sounds, singing songs with sound substitutions).

\section{Activity-Based Control (ABC)}

In the $\mathrm{ABC}$ condition, parents received weekly resources for activities to engage in with their children over the 6-week period, but they did not attend a workshop. The themes were "art" "get up and active" "healthy food" "looking after yourself" "music" and "science." Each week's activities were designed to be enjoyable and to take a similar amount of time interacting as the activities in the book conditions.

\section{Follow-Up Data Collection Procedure}

One year after the implementation phase ended, parents of participating children were contacted to arrange follow-up data collection. Parents were given questionnaires to fill out in their own time and were recorded reading Esau the Paw to their children (Gurney \& Bennett, 2014). These shared reading sessions were arranged with parents at their preferred location, typically at home or the child's school, although some also occurred at the mother's work or a university research room.

\section{Data Analysis}

Using ANCOVA with posttest data as the outcome and pretest as a covariate is argued to be the best approach to examine between-group differences in treatment effects, even when baseline data is not equal across groups (Senn, 2006). Some violations of normality, equality of variance and/or outliers existed for talk variables. Using Bias-Corrected accelerated (BCa) bootstrap confidence intervals on posttest variables using ANCOVA gives a robust estimate of significance for conditions of unequal variance (SadooghiAlvandi \& Jafari, 2013). Bootstrapping is also robust when data contain outliers, unequal sample sizes, heteroscedasticity, and non-normal distributions (Field, 2013). For variables which contained violations of the assumptions required for a robust $F$ statistic, bootstrapped confidence intervals based on controlled means were reported. Assumptions were considered violated if skew was greater than two, or the data contained extreme cases.
Univariate ANCOVAs were used to test for group differences at follow-up on shared reading and FIQ-NZ, controlling for relevant pretest variables. All ANCOVAs except home-based involvement had the same measure at pretest as the control variable. Because the home-based involvement measure was not collected at pretest, we used parentreported confidence in teaching children to read as the pretest covariate in comparisons of follow-up FIQ-NZ homebased involvement. Parent-reported confidence was included as a covariate given previous findings of parental efficacy as a correlate of involvement (Hoover-Dempsey et al., 2005; McDowall et al., 2017) and the obtained correlation between pretest confidence and follow-up FIQ-NZ home-based involvement $(r=.42, p=.002)$ in this study. Parent implementation and frequency still using the program data were compared using individual univariate ANOVA. Follow-up tests on ANCOVAs and ANOVAs were conducted with least standard differences, equivalent to independent-samples $t$ tests on adjusted means. We did not adjust for multiple comparisons for two reasons: (a) limited power due to small $\mathrm{N}$, and (b) because tests adjusting for multiple comparisons do not offer relevant bootstrap CIs. Confidence intervals based on bootstrapping are reported for all variables giving additional information about population estimates. Cohen's $d$ scores were calculated by converting standard error (SE) scores for normally distributed variables or BCa-bootstrapped SE scores for non-normally distributed variables into standard deviation (SD) scores using the formula $\mathrm{SD}=\mathrm{SE} \times \sqrt{n}$. This was then converted into a $d$ score using the formula $d=\left(M_{2}-M_{1}\right) / \mathrm{SD}$ pooled. This calculation allowed the more robust bootstrapped SE to be used in calculations involving variables violating normality assumptions.

\section{Results}

\section{Implementation}

Implementation for the entire sample was reported by Riordan et al. (2021), with implementation data available for 65 independent dyads. (Younger sibling participants were excluded from comparative analyses.) During the implementation phase, $73 \%$ of these participants participated in at least some activities every week of the 6-week implementation phase and returned all implementation data. Of these, $78.3 \%$ were from RRR, $63.6 \%$ from SSS, and $75.0 \%$ from $\mathrm{ABC}$. When looking at those participants with followup data, 50 handed in more than one weekly stamp chart ( 3 were excluded). ANOVA showed group differences in implementation $F(2,47)=8.48, p=.001$. Follow-up analyses showed that, on average, the proportion of activities 
endorsed by participants retained at 1-year follow-up in $\mathrm{RRR}(M(\mathrm{SE})=.92(.03)$ were higher than $\mathrm{ABC} M(\mathrm{SE})=.74$ (.04) $p=.001, \mathrm{BCa}$ CI $[.11, .25], d=1.29$ and than SSS $M$ $(\mathrm{SE})=.77(.04) p=.002$, BCa CI $[.04, .25], d=1.08$.

\section{Parent Shared Book Reading Extratextual Talk}

Descriptive statistics and analyses for parent extratextual talk during shared book reading are shown in Table 2.

\section{Parent Meaning Talk}

Univariate ANCOVAs controlling for relevant pretest variables showed that parents in the RRR group used more meaning talk at 1-year follow-up than parents in $\mathrm{ABC}$ or SSS. When specific types of meaning talk were examined, parents in RRR used more predictions/inferences and evaluations than the ABC or SSS group, again with medium to large effect sizes, even though parents in SSS used more predictions/inferences and evaluations at baseline. RRR parents also used more relating to world talk than SSS parents, which included both general knowledge and word definitions. Both RRR and SSS groups used more open-ended questions than the $\mathrm{ABC}$ group. Effect sizes for these variables were medium to large.

\section{Parent Print and Sound Talk}

Parents in the SSS group used statistically more print and sound talk at 1-year follow-up than parents in ABC and RRR (see Table 2). These differences had large effect sizes. The SSS group used more sound talk at baseline violating the assumption of independence; however, analyses controlled for baseline sound talk.

\section{Child Shared Book Reading Extratextual Talk}

Descriptive statistics and results of between-group comparisons of children's extra-talk during shared book reading at 1-year follow-up are shown in Table 3.

\section{Child Meaning Talk}

Univariate ANCOVAs showed that children's overall meaning talk did not differ by group at follow-up; however, groups differed on some specific types of meaning talk, controlling for baseline levels, shown in Table 3. Similar to their parents, children in RRR used more relating to world talk than those in ABC or in SSS. Children in RRR also made more inferences than those in SSS. This variable was heteroscedastic, as children in the SSS group made more inferences at pretest. The magnitude of Cohen's $d$ suggested medium effects. No other statistically significant differences were found for child meaning talk variables.

\section{Child Print and Sound Talk}

Results for children's print and sound talk at 1-year follow-up were similar to those found for parents (see Table 3). Children in the SSS group used statistically more print talk at 1-year follow-up than those in ABC, or those in RRR. Children in SSS also used more sound talk than those in $\mathrm{ABC}$, or those in RRR. Effect sizes were large.

\section{Parent Continued Use of Project Activities}

Across conditions, the majority of parents endorsed still using program activities. Yet, the number of parents reporting still using activities varied by condition (linear-by-linear association $\left.\chi^{2}(1 d f)=5.43, p=.020\right)$. Nearly all parents from RRR $(18 / 20,90 \%)$ reported still using activities, as did most parents from SSS (13/16, 81.25\%), compared to just over half of parents from $\mathrm{ABC}(9 / 16,56.25 \%)$. Endorsements of continued use did not differ between the two preventive intervention conditions (Fisher's exact test (two-sided), $p=.637$ ), nor between SSS and ABC (Fisher's exact test (two-sided), $p=.252$ ). However, parents who participated in RRR were more likely to endorse they continued to use project activities than those in $\mathrm{ABC}$ (Fisher's exact test (two-sided), $p=.049$ ) and to report using them more frequently (adjusted $M(\mathrm{SD})=3.15(1.58)$ ) than those in $\mathrm{ABC}$ (adjusted $M(\mathrm{SD})=1.19(1.58)$ ), $d=1.24$, BCa CI $[.743,3.10], F(2,46)=6.88, p=.001$. The effect size for the difference in frequency of reported use between RRR and $\mathrm{ABC}$ was large.

\section{Parent Involvement}

Analyses of the FIQ-NZ scales at 1-year follow-up found group differences for school-based involvement $(F(2,43)=5.61$, $p=.007)$ and home-based involvement $(F(2,43)=4.32$, $p=.019)$. Post hoc analyses for school-based involvement showed the RRR group (adjusted $M(\mathrm{SD})=2.88(.53)$ reported higher school-based involvement scores than $\mathrm{ABC}$ (adjusted $M(\mathrm{SD})=2.31(.53), p=.004, d=1.06, \mathrm{BCa}$ CI $[.20, .95]$, and SSS (adjusted $M(\mathrm{SD})=2.39(.53) p=.014, d=1.08, \mathrm{BCa}$ CI $[.11, .87]$. Further analysis for home-based involvement showed those in RRR (adjusted $M(S D)=3.35(.43)$ ) generally reported higher home-based involvement than those in SSS (adjusted $M(\mathrm{SD})=2.89(.43)), p=.006, d=1.08, \mathrm{BCa}$ CI $[.17$, .77]. Groups did not differ on home-school communication. 


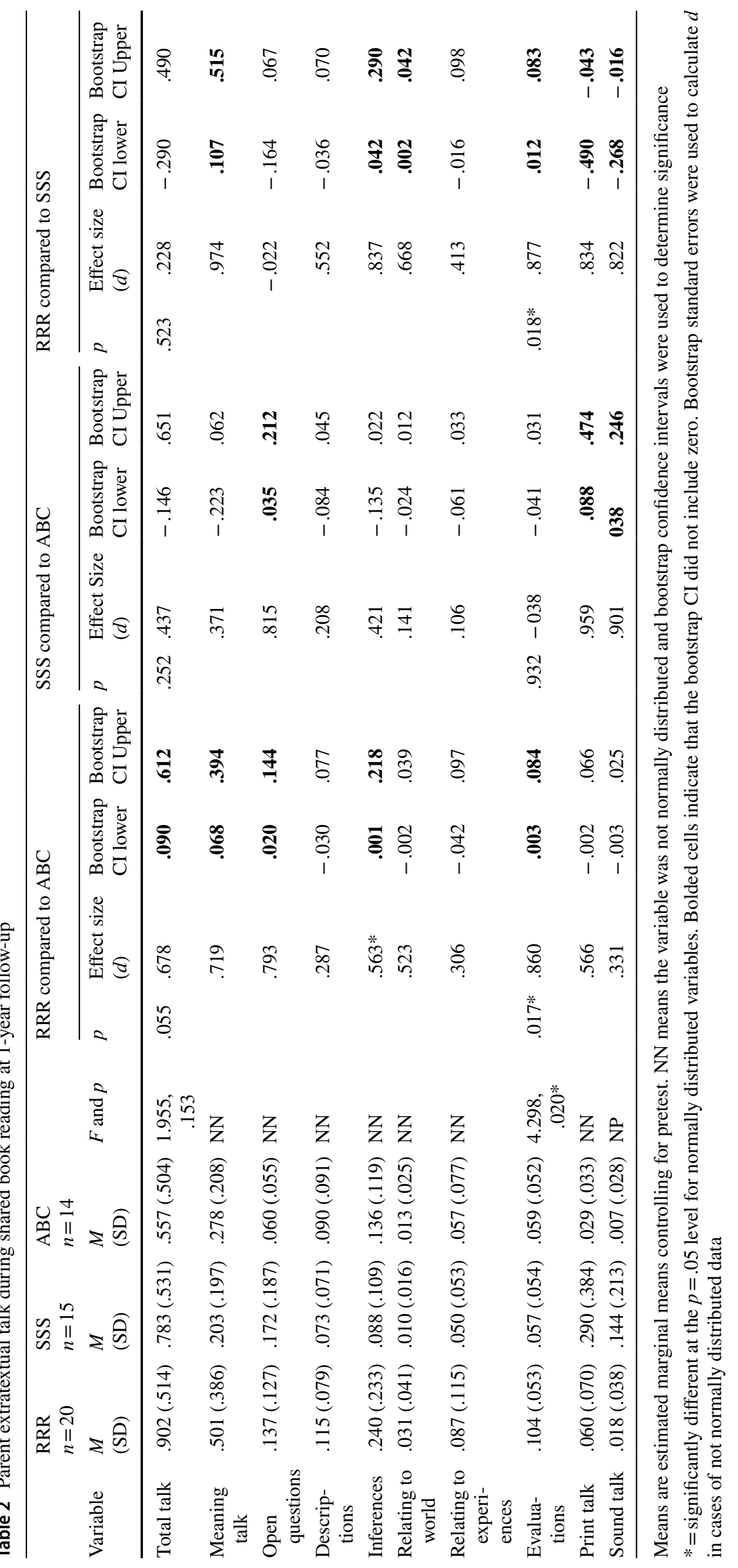




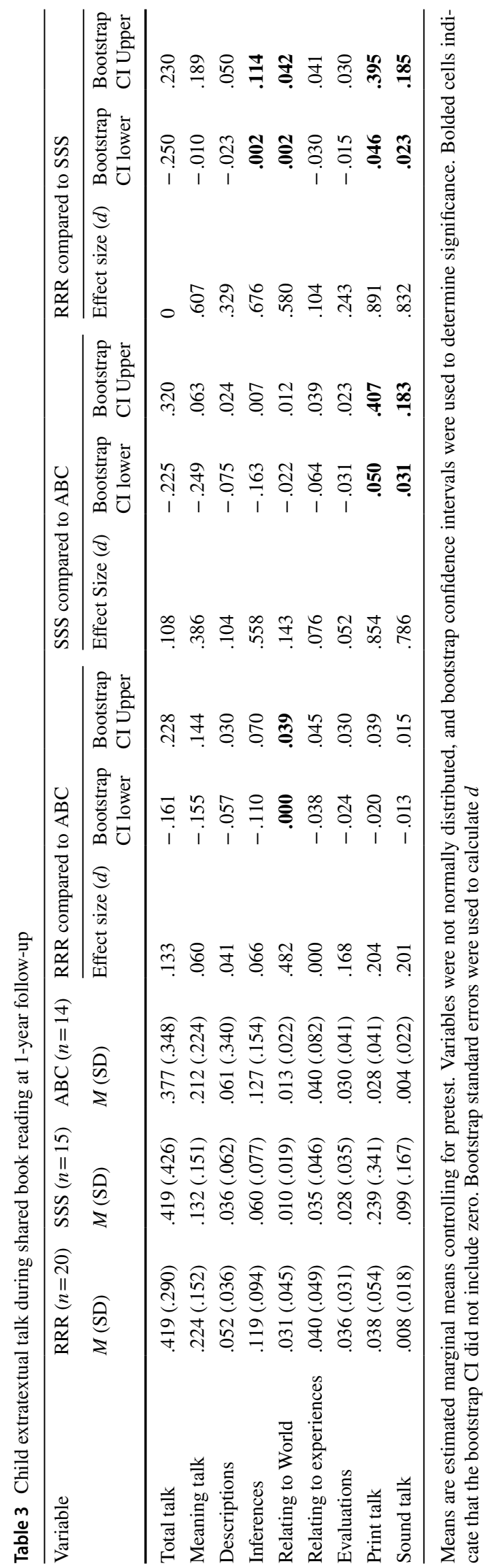

Statistical group differences in FIQ-NZ scales had large effect sizes.

\section{Discussion}

The main aims of this study were to evaluate (a) whether participation in a parent-preschooler shared reading program would show lasting effects on parent-child interactions after children had started school and reading instruction, and (b) whether this involvement in children's early learning was associated with further parent involvement after school entry. Parents and children in both reading conditions showed condition-specific effects in extratextual talk during shared reading 1 year later. Parents from reading groups were also more likely to report using program techniques since school started than parents in the control group, with the meaning-talk-focused (RRR) group reporting a higher frequency of continued use than the control (ABC) group. Parent ratings suggested that, on average, parents in both reading conditions continued to use activities weekly, with parents from RRR reporting using project activities around 2-3 times per week compared to about once every couple of weeks for ABC. Furthermore, parents in RRR reported more school-based involvement than parents in the other groups.

\section{Long-Term Effects of RRR and SSS on Specific Shared Reading Techniques}

Parents in both shared reading groups were more likely to report still using program-related skills since school started than parents in $\mathrm{ABC}$. Recordings of shared reading interactions confirmed that both reading groups showed continued use of condition-specific shared reading strategies. This sustained change in talk during shared reading is likely to be due to the ease of program implementation. NZ parents report frequent book-sharing with their children (Morton et al., 2017); in a needs assessment prior to our program, parents identified shared reading as a preferred vehicle for developing children's early language and literacy skills (Schaughency et al., 2016). Thus, our focus on shared reading may have promoted continued use by building on something families already did and enjoyed rather than introducing activities that parents may struggle to find time for, making it easier to continue to implement after the program had ended. We reduced barriers to implementation by providing books, prompts within the books, and allowing parents plenty of opportunity to practice and internalize the targeted skills. Our approach is consistent with recommendations for parent programs by Sabol et al. (2018). Sabol and colleagues suggest that building 
on human capital, reducing barriers to implementation, and giving parents opportunity to practice new skills enhance parent learning and behavior change even when contact time with professionals may be limited. Project elements also aimed to engage children, given the facilitative role of children's invitations to parents' involvement, along with the promotive role of children's interests in literacy activities for learning and development (Schaughency et al., 2020). Subjective reports suggest children are often excited to receive new books, asking adults to read to them (Schaughency et al., 2019, 2020), likely promoting implementation. Documenting implementation is a challenge (Logan et al., 2019); therefore, we incorporated a child-friendly activity as a framework for implementation logs, similar to those used and enjoyed by children during baseline assessment. This strategy was successful, as nearly all participants provided implementation data, with most (73\%) participants providing implementation data across the 6-week implementation phase. Although engagement was not directly assessed, condition specific benefits for children's extratextual talk were found at posttest (Riordan et al., 2021), and maintained at follow-up, as discussed below.

\section{Observed Extratextual Talk Specific to RRR}

Parents' overall use of meaning-related talk was larger in the RRR group than in SSS or ABC, and the specific types of meaning talk used showed intriguing patterns. Parents in RRR used more prediction/inference and evaluation talk than those in other groups, and used more relating to world talk than SSS. Talk which predicts or infers is typically considered higher level and is associated with fostering language skills (Reese et al., under review; Tompkins et al., 2017), important for reading comprehension (Silverman et al., 2020). Evaluation talk was often used as a way to follow and extend children's utterances. For example, if a child pointed out "they're laughing at the cat!", parents often replied with an evaluation, such as "Do you think that's a nice thing to do?" or "That's not very nice!" Moreover, parents who participated in RRR did not use more descriptive talk (labels and picture descriptions), considered lower-level, with more limited promotive effects for scaffolding development of older preschool children (Tompkins et al., 2017).

Children in RRR specifically used more talk relating book content to general knowledge, suggesting that they are responding to their parents' invitations for talk during reading and sharing what they have learned about book events, including new words, forming important connections between the story and the outside world. Recall that parents in RRR were prompted after each book reading to reminisce about personal experiences related to the book; thus, linking the book to the child's world may have contributed to this finding.

\section{Observed Extratextual Talk Specific to SSS}

Both preventive intervention conditions were designed to promote children's developing cognitive-linguistic skills relevant to later-reading acquisition, although SSS targeted a narrower skillset (i.e., phonological awareness skills developing during the preschool period; Anthony \& Francis, 2005). However, we found parents and children in SSS used not only more sound-related talk but also more print-related talk during the follow-up shared reading interaction. These results are consistent with those reported by Riordan et al. (2021) at posttest. Thus, some skill extension may be happening naturally, as parents extend their use of extratextual talk from the sound-focused talk targeted to also make more references to print as well. Moreover, in a separate open community trial of a sequence of workshops for parents of preschool parents based on RRR and SSS, parents likewise reported more print-related talk during reading at follow-up conducted at school entry and the start of formal reading instruction (Schaughency et al., 2020).

\section{Effects of Program on Broader Parent Involvement}

On average, participating parents' reported involvement on the FIQ-NZ were consistent with, or exceeded, those previously reported (Garbacz et al., 2015; McDowall et al, 2017). Previous research led us to expect both reading groups would have higher home-based FIQ-NZ scores at 1 year (DeLoatche et al., 2015). Instead, parents from RRR reported higher levels of home-based involvement than those from SSS, despite no differences between reading conditions in numbers of parents who continued project specific home-based support for literacy learning and reported frequency of use at follow-up discussed above. There were no between-group differences in home-school communication on the FIQ-NZ.

In addition, parents from RRR reported more schoolbased involvement than those in ABC or SSS. One possibility for higher school-based involvement for parents who participated in RRR relates to children's skills. If children in RRR talk more about their knowledge during shared reading sessions, as we found they did with parents, teachers may evaluate those children positively. Follow-up evaluation of children's independently assessed oral language skills suggest children who participated in RRR display higher levels of oral narrative skills (Reese et al., under review), and their teachers rated them to display higher levels of participation and contribution in class (Clifford et al., 2016). Teachers' 
positive evaluations of children, in turn, may impact teachers' explicit and implicit encouragement of parents to become involved in school activities (Garbacz et al., 2017; McDowall et al., 2017).

Another factor potentially contributing to possible differences in involvement between SSS and RRR could be perceived alignment between approaches used in the shared reading conditions and those used in beginning reading. Teachers of beginning readers in NZ may be more confident in teaching meaning-based elements during reading instruction and be more likely to attend to these elements during shared reading activities with children rather than explicit phonetic teaching (Arrow et al., 2019). Given this, parents who participated in RRR may have perceived a better fit between the meaning-focused approaches of RRR and their children's experiences in beginning reading instruction.

Skills targeted in SSS are important for beginning reading (Petscher et al., 2020), and evaluations suggest that participation in SSS is associated with benefits for children's literacy development (Schaughency et al., 2021). Yet, the connection between skills emphasized in SSS and those used in children's beginning reading may not be obvious to parents for several reasons. First, development is a moving target, and earlier developing phonological awareness activities emphasized in SSS may have given way to activities involving more advanced skills. Second, although the activities of SSS involving phonological awareness and children's active participation in the production of speech sounds are thought to contribute to development of decoding skills (Ehri, 2014), other early literacy skills, such as alphabetic knowledge, may be more apparent foundational skills to parents of beginning readers. Indeed, some parents in SSS commented the program should have taught their children letter names. Taken together, results may suggest a need to provide parents with further information about developing phonological awareness skills and their role in reading acquisition. They also point to the potential importance of perceived consistency between the content of home literacy programs and what children are learning at school (Crosby et al., 2015).

\section{Strengths, Limitations, and Future Directions}

Strengths include the randomized design, consideration of adherence during the implementation phase, and observations of quality of shared reading as well as reported frequency of sustained use of project activities after the transition to primary school. A main limitation of this study was the sample size, which, coupled with the distributional characteristics of some variables, limited the power of the statistical analyses that could be performed as well as the strength of our conclusions. Some analyses of parent-child talk were also potentially affected by group differences at pretest, such that higher levels of pretest talk variables in the
SSS group may have resulted in lower adjusted means for those variables at 1 -year follow-up, thereby potentially attenuating positive findings for SSS. Moreover, our comparisons of home-based involvement at follow-up were limited by the lack of the same measure at pretest, addressed analytically with a correlate as the pretest covariate.

Adherence and continued use of project activities were measured via self-report, potentially subject to social desirability. Although our implementation charts may have encouraged participation, such records may yield psychometrically adequate data (Pelham et al., 2005). Nevertheless, even though parents endorsed project activities were implemented, our procedure did not capture how activities were implemented nor children's engagement with, and responsiveness to, parents' implementation. Future work could consider methods to audio and/or video record adult-child reading interactions during the implementation phase. This would allow for consideration of these variables as potential moderators or mediators of condition effects.

Finally, attrition analyses revealed that participants with follow-up data generally displayed higher levels of implementation, potentially influencing obtained results and limiting generalizability to those with lower levels of implementation. This study is also limited demographically, as all participants had children attending center-based early childhood settings, volunteered to participate in this research, and lived in the same small urban area. Future research should expand these demographics to include different educational contexts.

Future research should also examine the effects of the quality of shared reading during preschool school and early schooling, and parent involvement in beginning schooling, on longer-term targeted and/or more general aspects of children's academic success. These extensions could be further explored as a function of alignment between program-related parent skills and teaching techniques in school. Other extensions could address teacher attitudes toward parent involvement, as parents' perceptions of teachers' beliefs about the importance and helpfulness of parents' involvement can influence how much they become involved (McDowall et al., 2017), and other psychosocial factors affecting relationships between parents and school personnel (Kim \& Sheridan, 2015).

Future research would benefit from looking at potential mechanisms involved in the transmission of preschool effects into family involvement and child achievement. Loughlin-Presnal and Bierman (2017) found that the effect of a preschool parenting program on child achievement at school was mediated by parent expectations of children's academic skills. This study did not measure parent academic expectations, an identified correlate of children's educational achievement (Boonk et al., 2018), and the Loughlin-Presnal and Bierman (2017) study did not measure involvement. 
Both studies, however, show lasting effects from a preschool parent program. Therefore, further insight into the mechanisms behind longer-term changes in parent beliefs and behavior and child academic achievement could be gained if future research investigates possible interrelations between potential outcomes associated with preschool programs. These outcomes may include parents' efficacy in supporting their children's learning, parents' academic expectations for their children, parents' involvement in children's learning, and children's developing competencies. This suggested research would address aspects of the call to look further into the mechanisms behind successful family involvement (Garbacz et al., 2017).

Given the importance for both phonological awareness and meaning-related oral language skills for later-reading achievement (e.g., Dickinson et al., 2019), future research should also evaluate implementation of both RRR and SSS. In an open community trial, parents endorsed receiving content related to both conditions (Schaughency et al., 2020). This research team is currently examining sequential delivery of RRR and SSS modules with home-based early childhood educators (Schaughency et al., 2019).

\section{Conclusion}

The continued use of condition-specific shared reading techniques by parents who participated in SSS or RRR 1 year after a shared reading program indicates the potential benefit of the light-touch Tender Shoots approach to domain-specific parent education followed by supported implementation. A notable issue in many programs delivered by researchers or early childhood educators is the lack of continued support once the program ends and/or when children transition to other teaching providers such as schools (Sarama \& Clements, 2018). We have shown that parents continue to display interactional skills we aimed to promote in shared reading with their children a year after a program ended, with evidence of parents' continued implementation through self-report and observation of their shared reading interactions. The literature shows that shared reading programs can be effective for increasing parents' shared reading competence in the short term (Dowdall et al., 2020). Our findings build on this by increasing confidence that shared reading skills can carry over into longer-term behavior change. Furthermore, participating in RRR was associated with parents' reported involvement with children's schooling. These findings suggest that specific experiences with children's learning may influence family involvement, and schools and practitioners can consider efforts to engage parents' involvement before formal schooling begins.
Supplementary Information The online version contains supplementary material available at https://doi.org/10.1007/s12310-022-09505-6.

Acknowledgements This research was supported in part by University of Otago research grants to Elizabeth Schaughency and Elaine Reese.

Funding Open Access funding enabled and organized by CAUL and its Member Institutions.

Open Access This article is licensed under a Creative Commons Attribution 4.0 International License, which permits use, sharing, adaptation, distribution and reproduction in any medium or format, as long as you give appropriate credit to the original author(s) and the source, provide a link to the Creative Commons licence, and indicate if changes were made. The images or other third party material in this article are included in the article's Creative Commons licence, unless indicated otherwise in a credit line to the material. If material is not included in the article's Creative Commons licence and your intended use is not permitted by statutory regulation or exceeds the permitted use, you will need to obtain permission directly from the copyright holder. To view a copy of this licence, visit http://creativecommons.org/licenses/by/4.0/.

\section{References}

Anthony, J. L., \& Francis, D. J. (2005). Development of phonological awareness. Current Directions in Psychological Science, 14(5), $255-259$.

Arrow, A. W., Braid, C., \& Chapman, J. W. (2019). Explicit linguistic knowledge is necessary, but not sufficient, for the provision of explicit early literacy instruction. Annals of Dyslexia, 69(1), 99-113.

Barnett, W. S. (2011). Effectiveness of early educational intervention. Science, 333(6045), 975-978.

Boonk, L., Gijselaers, H. J. M., Ritzen, H., \& Brand-Gruwel, S. (2018). A review of the relationship between parental involvement indicators and academic achievement. Educational Research Review, 24, 10-30. https://doi.org/10.1016/j.edurev. 2018.02.001

Canfield, C. F., Miller, E. B., Shaw, D. S., Morris, P., Alonso, A., \& Mendelsohn, A. (2020). Beyond language: Impacts of shared reading on parenting stress and early parent-child relational health. Developmental Psychology, 56(7), 1305-1315.

Clifford, A., Schaughency, E., Eton, J., Barrett-Young, A., Rouse, S., Reese, E., \& Carroll, J. (2016). Te Phihnga: Growing adults' capacity to nurture young children's emergent key competencies. Presentation at the 9the Educational Psychology Forum, Massey University, Albany, New Zealand, 21 November 2016.

Crosby, S. A., Rasinski, T., Padak, N., \& Yildirim, K. (2015). A 3-year study of a school-based parental involvement program in early literacy. Journal of Educational Research, 108(2), 165-172.

DeLoatche, K. J., Bradley-Klug, K. L., Ogg, J., Kromrey, J. D., \& Sundman-Wheat, A. N. (2015). Increasing parent involvement among head start families: A randomized control group study. Early Childhood Education Journal, 43, 271-279.

Dickinson, D. K., Nesbitt, K. T., \& Hofer, K. G. (2019). Effects of language on initial reading: Direct and indirect associations between code and language from preschool to first grade. Early Childhood Research Quarterly, 49, 122-137. https://doi.org/10. 1016/j.ecresq.2019.04.005

Dowdall, N., Melendez-Torres, G. J., Murray, L., Gardner, F., Hartford, L., \& Cooper, P. J. (2020). Shared picture book reading interventions for child language development : A systematic 
review and meta-analysis. Child Development, 91(2), e383e399. https://doi.org/10.1111/cdev.13225

Ehri, L. C. (2014). Orthographic mapping in the acquisition of sight word reading, spelling memory, and vocabulary learning. Scientific Studies of Reading, 18(1), 5-21. https://doi.org/10.1080/ 10888438.2013 .819356

Fahy, K. M., Lee, A., \& Milne, B. J. (2013). New Zealand socio-economic index 2013. Statistics New Zealand Tatauranga Aotearoa.

Fantuzzo, J., Tighe, E., \& Childs, S. (2000). Family involvement questionnaire: A multivariate assessment of family participation in early childhood education. Journal of Educational Psychology, 92(2), 367-376.

Field, A. (2013). Discovering statistics using IBM SPSS statistics (4th ed.). Sage.

Flack, Z. M., Field, A. P., \& Horst, J. S. (2018). The effects of shared storybook reading on word learning: A meta-analysis. Developmental Psychology, 54(7), 1334-1346.

Garbacz, S. A., Herman, K. C., Thompson, A. M., \& Reinke, W. M. (2017). Family engagement in education and intervention: Implementation and evaluation to maximize family, school, and student outcomes. Journal of School Psychology, 62, 1-10.

Garbacz, S. A., McDowall, P. S., Schaughency, E., Sheridan, S. M., \& Welch, G. W. (2015). A multidimensional examination of parent involvement across child and parent characteristics. The Elementary School Journal, 115(3), 384-406.

Garbacz, S. A., \& Sheridan, S. M. (2011). A multidimensional examination of New Zealand family involvement in education. School Psychology International, 32(6), 600-615.

Gillon, G., McNeill, B., Scott, A., Denston, A., Wilson, L., Carson, K., \& Macfarlane, A. H. (2019). A better start to literacy learning: Findings from a teacher-implemented intervention in children's first year at school. Reading and Writing, 32, 1989-2012. https:// doi.org/10.1007/s11145-018-9933-7

Green, C. L., Walker, J. M. T., Hoover-Dempsey, K. V., \& Sandler, H. M. (2007). Parents' motivations for involvement in children's education: An empirical test of a theoretical model of parental involvement. Journal of Educational Psychology, 99(3), 532-544.

Greenwood, C., Carta, J., Walker, D., Watson-Thompson, J., Gilkerson, J., Larson, A. L., \& Schnitz, A. (2017). Conceptualizing a public health prevention intervention for bridging the 30 million word gap. Clinical Child and Family Psychology Review, 20, 3-24.

Gurney, C., \& Bennett, J. (2014). Esau the Paw. Scholastic New Zealand.

Hoover-Dempsey, K., Walker, J., Sandler, H., Whetsel, D., Green, C., Wilkins, A., \& Closson, K. (2005). Why do parents become involved? The Elementary School Journal, 106(2), 105-130.

Kim, E., \& Sheridan, S. (2015). Foundational aspects of family-school connections: Definitions, conceptual frameworks and research needs. In S. Sheridan \& E. Kim (Eds.), Foundational aspects of family-school partnership research (pp. 1-14). Springer.

Landis, J. R., \& Koch, G. G. (1977). The measurement of observer agreement for categorical data. Biometrics, 33(1), 159-174.

Logan, J. A. R., Dynia, J. M., Justice, L. M., \& Sawyer, B. (2019). Caregiver implementation of a home-based reading program with their children with disabilities: Patterns of adherence. Learning Disability Quarterly, 42(3), 135-146. https://doi.org/10.1177/ 0731948718786231

Loughlin-Presnal, J. E., \& Bierman, K. L. (2017). Promoting parent academic expectations predicts improved school outcomes for low-income children entering kindergarten. Journal of School Psychology, 62, 67-80.

Manz, P., Fantuzzo, J., \& Power, T. (2004). Multidimensional assessment of family involvement among urban elementary students. Journal of School Psychology, 42, 461-475.
McDowall, P. J. (2014). Parent-involvement in children's reading development: Parent and teacher perceptions, and child reading outcomes. Doctoral Dissertation, University of Otago.

McDowall, P. S., Taumoepeau, M., \& Schaughency, E. (2017). Parent involvement in beginning primary school: Correlates and changes in involvement across the first two years of school in a New Zealand sample. Journal of School Psychology, 62, 11-31.

McWayne, C. M. (2015). Family-school partnerships in a context of urgent engagement: Rethinking models, measurement, and meaningfulness. In S. M. Sheridan \& E. M. Kim (Eds.), Foundational aspects of family-school partnership research (1st ed., pp. 103122). Springer.

Ministry of Education. (2014). Criteria for colour wheel levels. The New Zealand Curriculum Update, 28.

Ministry of Education. (2018). Ministry funding deciles. https://parents. education.govt.nz/primary-school/schooling-in-nz/ministry-fundi ng-deciles/

Ministry of Education. (2019). Different types of primary and intermediate schools. https://parents.education.govt.nz/primary-school/ schooling-in-nz/different-types-of-primary-and-intermediateschools/

Morton, S., Grant, C., Berry, S., Walker, C., Corkin, M., de Castro, T., Atatoa Carr, P., Bandara, D., Mohal, J., Bird, A., Underwood, L., \& Fa' alili-Fidow, J. (2017). Growing up in New Zealand: A longitudinal study of New Zealand children and their families. Now we are four: Describing the preschool years. https://cdn.auckland. ac.nz/assets/growingup/research-findings-impact/GUiNZ_Now\% 20we\%20are\%20four\%20report.pdf

Murray, L., Pascalis, L. D., Tomlinson, M., Vally, Z., Dadomo, H., Maclachlan, B., Woodward, C., \& Cooper, P. J. (2016). Randomized controlled trial of a book-sharing intervention in a deprived South African community: Effects on carer-infant interactions, and their relation to infant cognitive and socio-emotional outcome. Journal of Child Psychology and Psychiatry, 57(12), 1370-1379.

Nonoyama-Tarumi, Y., \& Willms, J. D. (2010). The relative and absolute risks of disadvantaged family background and low levels of school resources on student literacy. Economics of Education Review, 29, 214-224.

Pelham, W. E., Jr., Fabiano, G. A., \& Massetti, G. M. (2005). Evidencebased assessment of attention deficit hyperactivity disorder in children and adolescents. Journal of Clinical Child \& Adolescent Psychology, 34(3), 449-476. https://doi.org/10.1207/s15374424j ccp3403_5

Petscher, Y., Cabell, S. Q., Catts, H. W., Compton, D. L., Foorman, B. R., Hart, S. A., Lonigan, C. J., Phillips, B. M., Schatschneider, C., Steacy, L. M., Terry, N. P., \& Wagner, R. K. (2020). How the science of reading informs 21 st-century education. Reading Research Quarterly, 55(S1), S267-S282. https://doi.org/10.1002/rrq.352

Reese, E. (2013). Tell me a story: Sharing stories to enrich your child's world. Oxford University Press.

Reese, E. (2019). Learning language from books. In J. S. Horst \& J. von Koss Torkildsen's (Eds.), International handbook of language development (pp. 462-484). Routledge/Taylor \& Francis.

Reese, E., Barrett-Young, A., Gilkison, L., Carroll, J., Das, S., Riordan, J., \& E. Schaughency (under review). Tender Shoots: A parent book-reading and reminiscing program to enhance children's oral narrative skills. Reading and Writing.

Rimm-Kaufman, S. E., \& Pianta, R. C. (1999). Patterns of familyschool contact in preschool and kindergarten. School Psychology Review, 28(3), 426-438.

Riordan, J., Reese, E., Das, S., Carroll, J., \& Schaughency, E. (2021) Tender Shoots: A randomized controlled trail of two sharedreading approaches for enhancing parent-child interactions and 
children's oral language and literacy skills. Scientific Studies of Reading. https://doi.org/10.1080/10888438.2021.1926464

Riordan, J., Reese, E., Rouse, S., \& Schaughency, E. (2018). Promoting code-focused talk: The rhyme and reason for why book style matters. Early Childhood Research Quarterly, 45, 69-80.

Sabol, T. J., Sommer, T. E., Sanchez, A., \& Busby, A. K. (2018). A new approach to defining and measuring family engagement in early childhood education programs. AERA Open, 4(3), 1-12.

Sadooghi-Alvandi, S. M., \& Jafari, A. A. (2013). A parametric bootstrap approach for one-way ANCOVA with unequal variances. Communications in Statistics-Theory and Methods, 42(14), 2473-2498.

Salmon, K., \& Reese, E. (2016). The benefits of reminiscing with young children. Current Directions in Psychological Science, 25(4), 233-238.

Sarama, J., \& Clements, D. H. (2018). Promoting positive transitions through coherent instruction, assessment, and professional development: The TRIAD scale-up model. In A. J. Mashburn, J. LoCasale-crouch, \& K. C. Pears (Eds.), Kindergarten transitions and readiness: Promoting cognitive, social-emotional, and self-regulatory development (pp. 327-348). Springer International Publishing.

Schaughency, E., Das, S., Carroll, J., Johnston, J., Robertson, S. J., \& Reese, E. (2014). Getting ready for school: Exploring caregivers' implementation of a parent-mediated school readiness programme. 7th Educational Psychology Forum. University of Otago, Dunedin, New Zealand, 18-19 November.

Schaughency, E., Reese, E., Healey, D., Carroll, J., Cross, T., Johnson, J. Fagan, H., \& Burrowes, R. (2019). Supporting teaching and learning in home-based early childhood education. Teaching and Learning Research Initiative. http://www.tlri.org.nz/tlri-resea rch/research-progress/ece-sector/supporting-teaching-and-learn ing-home-based-early-0

Schaughency, E., Linney, K., Carroll, J., Riordan, J., Das, S. \& Reese, E. (2021, February). Tender Shoots: Beginning reading outcomes. Paper presented in J. Carroll (Convenor), Tender Shoots: A shared reading and oral language preventive intervention for parents, educators, and preschool children. Symposium presented at the 13th Educational Psychology Forum, University of Otago, Dunedin, New Zealand, 1-2 February.

Schaughency, E., Johnston, J., Das, S., Carroll, J., \& Reese, E. (2016). Embracing the spirit of ako: Growing partnerships between parents, early childhood educators and researchers. Early Childhood Folio, 20(2), 31-36.

Schaughency, E., Riordan, J., Reese, E., Derby, M., \& Gillon, G. (2020). Developing a community-based oral language preventive intervention: Exploring feasibility and social validity for families affected by the Canterbury Earthquakes. Infants \& Young Children, 33(3), 195-218. https://doi.org/10.1097/IYC.0000000000 000171

Sénéchal, M., \& Lefevre, J.-A. (2014). Continuity and change in the home literacy environment as predictors of growth in vocabulary and reading. Child Development, 85(4), 1552-1568.

Sénéchal, M., Whissell, J., \& Bildfell, A. (2017). Starting from home: Home literacy practices that make a difference. In R. K. Parrila, K. Cain, \& D. L. Compton (Eds.), Theories of reading development (pp. 383-407). Johns Benjamins Publishing Company.

Senn, S. (2006). Change from baseline and analysis of covariance revisited. Statistics in Medicine, 25(24), 4334-4344.

Silverman, R. D., Johnson, E., Keane, K., \& Khanna, S. (2020). Beyond decoding: A meta-analysis of the effects of language comprehension interventions on K-5 students' language and literacy outcomes. Reading Research Quarterly, 55, S207-S233.

Suggate, S. P., Lenhard, W., Neudecker, E., \& Schneider, W. (2013). Incidental vocabulary acquisition from stories: Second and fourth graders learn more from listening than reading. First Language, 33(6), 551-571.

Tompkins, V., Bengochea, A., Nicol, S., \& Justice, L. M. (2017). Maternal inferential input and children's language skills. Reading Research Quarterly, 52(4), 397-416.

Publisher's Note Springer Nature remains neutral with regard to jurisdictional claims in published maps and institutional affiliations. 